\title{
Institutioning and Community Radio. A comparative perspective
}

\author{
Roberto Cibin \\ Madeira Interactive \\ Technologies Institute \\ Funchal Portugal \\ roberto.cibin@m-iti.org
}

\author{
Maurizio Teli \\ Department of Planning \\ Aalborg University \\ Aalborg Denmark \\ maurizio@plan.aau.dk
}

\author{
Sarah Robinson \\ School of Applied Psychology \\ University College Cork \\ Cork Ireland \\ sarah.robinson@ucc.ie
}

\begin{abstract}
In recent years, designers have pointed to the role of institutioning, the way in which design processes and institutions are mutually shaped, constrained and enabled. This paper seeks to expand this discussion to the field of grassroots communities, a concept that enlightens the intersection between geographic communities and communities of interests/practice. The research draws on empirical work exploring the different experiences in four distinct socio-cultural and institutional contexts of Uganda, Ireland, Portugal and Romania to investigate how institutioning relate to the design of a new form of community radio based on an innovative technology. It also explores what are the practices that designers and grassroots communities use to manage and navigate potential constraints of institutioning, and offers comparative insight into how institutioning influences the design outcome. Using the concept of institutioning, we will show how, in this interaction, the grassroots communities in the making overcome the "space vs interest" dichotomy, and how institutions as well as communities play a role in shaping - and are potentially shaped by - the design process.
\end{abstract}

\section{CCS CONCEPTS}

- Human-centered computing $\rightarrow$ Collaborative and social computing $\rightarrow$ Empirical studies in collaborative and social computing

\section{KEYWORDS}

Participatory Design, Institutioning, Community, Community Radio

\section{ACM Reference format:}

Roberto Cibin, Maurizio Teli and Sarah Robinson. 2019. Institutioning and Community Radio. A comparative perspective. In Proceedings of the 9th International Conference on Communities and Technologies (C\&T 2019). 11 pages. https://doi.org/10.1145/3328320.3328392

Permission to make digital or hard copies of part or all of this work for personal or classroom use is granted without fee provided that copies are not made or distributed for profit or commercial advantage and that copies bear this notice and the full citation on the first page. Copyrights for third-party components of this work must be honored. For all other uses, contact the Owner/Author.

C\&T 2019, Fune 3-7, 2019, Vienna, Austria

(c) 2019 Copyright is held by the owner/author(s).

ACM ISBN 978-1-4503-7162-9/19/06.

https://doi.org/10.1145/3328320.3328392

\section{Introduction}

In recent years, design projects oriented toward the public realm, including geographical communities, communities of interests, and communities of practice, are questioned in relation to the interplay of design activities and institutions. This is symbolized by conversations drawing upon the 2017 publication of "Institutioning: Participatory Design, Co-Design and the public realm" by Huybrechts and colleagues [24], in which the authors explicitly question how design projects relate to the way in which institutions are culturally described, their actions framed, and their policy instruments enacted. This conversation is particularly relevant for the understanding of the relationship between technology design and communities. In this paper, we will try to underline how, when designing technologies for and with communities, institutions and the process of institutioning frame the possible actions for the design of community technology, with a particular emphasis on the design of a new technology for community radio.

To investigate the nexus between technology design, communities, and institutioning, this paper will focus, first, on the complexity of the concept of community, showing that communities are constantly in the making, achieved through social practices, including that of technology design. More specifically, we will focus on designing technologies for and with "grassroots communities", that are defined by Kuznetsov and colleagues as groups of people "often spontaneous, nonhierarchical and volunteer-driven [...] in contrast to the power structures implemented by traditional top-down organizations" [26:2]. This definition enlightens the intersection between the concepts of geographic communities and/or communities of practice, and therefore, offers a good starting point to investigate the relation between technology design for and with communities and institutions. Secondly, we will define and explore the concept of institutioning in technology design, showing how it can provide a valuable comparative framework, to understand how institutions affect the design process and how the design process can affect existing institutions, sometimes creating new institutions. The conclusion of the theoretical discussion will highlight our main research questions: how does the institutioning process enable and constrain design processes oriented to the making of grassroots communities? What are the 
practices that designers and communities develop to act in relation to institutions? How can design support grassroots communities' practices considering the different institutional contexts?

Empirically, we will draw on a design process aimed at the development of an ICT technology for the creation of community radio (hereafter $\mathrm{CR}$ ) stations with geographical communities in Uganda, Ireland, Portugal and Romania.

Using the concept of institutioning [24,28,34], we will show how the interactions between the design of technologies for and with communities and the different institutional frames have an influence on the making of grassroots communities of practice involved, and vice versa. More specifically, we will describe potential practices situated in between local institutioning processes and the broader institutional framework through a comparative analysis of the licencing processes that the design team have undergone to establish community radios in Uganda, Portugal, Ireland and Romania, using the technology at stake.

\section{The concept of community in technology design}

The title "Transforming Communities" and the description of the 9th International Conference on Communities and Technologies raises one of the main issues of this field of studies: the complexity of the notion of community. Although the boundaries of the concept vary, we can identify at least three main ways to define it. Firstly, communities of place, are communities that focus on physical features (space, location, boundaries); secondly, there are communities of interest, which are more process-oriented, and emphasise social connection [6,20]; and, thirdly, the concept of community of practice defines groups of people sharing similar activities, not necessarily within the same organisation, and in which there are social processes for an individual to move from a peripheral participation to be a recognized member of the community under observation [27].

When looking at this complexity from the perspective of a community-based technology design [15], the "space vs interest" dichotomy needs to be discussed as, usually, the geographical dimension is insufficient to define a sense of common belonging in groups. In the same geographical area there can be different imaginings of what community is [3], different ways of belonging, identities, interests, and practices [15]. In addition, Parra and colleagues [30] illustrate how the common idea of considering the community as a friendly strong connected village is value-laden, based on positive and nostalgic assumptions. In fact, they stress the continuous making of communities "as something that is more an achieved than an ascribed social attribute. Even when already there, community continues to be built, hindered or empowered" [30:34].

When working with communities, technology designers contribute to the making of communities. Considering communities as constantly in the making means to consider the interrelation between the geographical dimension, the interests people can express and the practices they engage with, and the process of technology design, as well as its output. A way through which this can be solved is looking at communities as part of a set of relations and the recent reflections on "grassroots communities" help in stressing this aspect, allowing for a rich conceptualisation of the relations between places, interests, and practices. Following the stimulus by Kuznetsov et al. [26], we refer to "grassroots communities" as the groups of people engaged in "grassroots activism", that is an "often spontaneous, non-hierarchical and volunteer-driven" effort to shape the context in which social activism takes place, often in contrast with "the power structures implemented by traditional top-down organizations”. As Kuznetsov et al. remind us, grassroots communities conceived in this way "face unique challenges, risks and constraints, which shape designs and appropriations of interactive systems." [26:2].

In this context, the geographical boundaries have a strong influence in defining the situation since they delimit the space in which the power relations takes place. This is much more evident in our post-industrial, platform society where often the externalities of various actions are local, but the responsibility for these actions and the information systems are global [31]. Given these premises, institutions play a role in shaping - and are potentially shaped by - the design process itself, and the recent efforts to understand and theorise institutioning as part of the design process can help to better describe the way through which design processes can contribute to communities in the making. In this paper, we focus on a project in its beginning, in which we can show how the design process is enabled and constrained by, and shapes, institutions.

\section{Institutioning in technology design}

Our starting point then is that communities are multi-faceted and complex, pointing to the need to understand the relations between societal processes defined by geographical boundaries, and the emergence of shared interests and practices in the community in the making. We pointed to grassroots communities, in their situated activism in relation to established forms of power as a conceptualisation that can help us moving forward in understanding how the design process participate to the making of the community itself. This conceptualization is able to let us observe the interaction between the design process, the making of the grassroots communities, and the institutional frameworks.

This is in line with recent contributions focusing on how the design process dealing with the "public realm", intended as the relational space beyond the boundaries fixed by the workplace, the classroom, or the hospital, is still strongly related to specific geographical locations as the starting point for empirical design work [24]. This research has pointed to a conceptual way of understanding societal processes at the interaction between IT design and the set of relations taking place in a geographical location. In the concept of institutioning, the focus is on the way through which design relates with, in a potentially transformative way, existing and new institutions [24,34] while the reference to institutional constraints stress how existing institutions can affect the design process at different levels [28]. In particular, we refer to the work of Huybrechts and colleagues [24], Lodato and Di Salvo [28], and Teli and colleagues [34]. These recent 
contributions have brought to the fore the relation between design and institutions. It should not be surprising that these contributions arose in the domain of participatory and co-design, as since its origins, as in the UTOPIA project [36], participatory design has been practising design that looks beyond product outcomes to understanding digital technologies as complex social, institutional, and technical things - a term that conveys the political character of design [e.g. 18].

In more detail, Huybrechts and colleagues [24] introduce the concept of institutioning, to define the practices to achieve change in the public realm through interaction and collaboration with the existing institutions, and the creation of new ones. Institutioning, for them, is a verb or practice that highlights the work that generally takes place behind the scenes of the situated participation of design projects. It is, therefore, "the process of articulating and reflecting on these process' dependencies on various institutional frames which can conversely, directly or indirectly lead to changes in a variety of institutional frames." [24:157].

They see this process as unfolding in three frames, as defined by Castell [9], which are able to inform and form the action within the institutions. Firstly, the set of policy documents, rules, laws and bylaws concurring to structure an institution defines the policy frames; secondly, the institutional action frames are the means and the structures of belief and perceptions specific to institutions that guide their actions; and thirdly, the metacultural frames are broader cultural narratives belonging to society which influence the nature of an institution [9,24,34]. Design processes depend on the institutional frames and, at the same time through institutioning, have an influence on them, not only at the local level but also at meso and macro level [24].

Lodato and Di Salvo [28] highlighted the various constraints that can emerge from the interaction between a design process and the institutional frames of a specific geographic location. The sandbox describes how the boundaries that institutions erect through preliminary decisions, often limit the possibility of making a change, and scaling up from the local level. The challenge is to cross the boundaries through the development of external attachments. The administrative gap happens in institutional contexts, where the resources needed for long-term planning are scarce, opaque or not available, and there is no possibility to develop a long-term strategy for the design of the technology. The challenge is to improve the tools to increase longterm planning. The ideological mismatch is present in those situations where the differences in the systems of values and meanings between the design process and the institutional frames are so intense that collaboration is not possible. In these cases, the challenge for the designers is to keep a certain level of ambiguity about the ideological positions finding implicit ways to foster agonism.

Teli and colleagues [34] have stressed the need of a comparative perspective, looking at the design practices enacted in a European project. They have concluded how, in a design project involving different localities relating to the same technology, the focus on institutioning can help to understand similarities and differences among the different grassroots initiatives involved and their contexts. The comparison and the connection of norms, voices, values, and actors coming from different institutions and contexts offer not only a clearer view on the community situations but also the possibility to develop new perspectives coming from a comparative point of view. Constraints and resources related to the interaction between design practices and existing local institutions can be underlined and managed in parallel with the other localities, while good local practices can be shared also with the goal of creating new shared institutions. We follow this line of thinking connecting technology design, grassroots communities in the making, and institutioning, asking ourselves the following questions: how does the institutioning process enable and constrain design processes oriented to the making of grassroots communities? What are the practices that designers and communities develop to act in relation to institutions? How can design support grassroots communities' practices considering the different institutional contexts?

To answer these questions, we rely on the intersection between the institutional frames [24] and the institutional constraints [28] that can emerge during the design process, in a design project that involves different localities and allows for a comparative approach [34]. In order to apply this analytical lens on the different communities and their specific design process, it is necessary to give a description of the particular kind of technology that they are dealing with and the social dynamics related to its use.

\section{Introducing Community Radio}

To discuss our main research questions, we focus on a specific technological practice, the establishment and operation of $\mathrm{CR}$ stations, that is able to relate with grassroots communities, to highlight geographical constraints and opportunities, and to show different nuances of institutional action. In fact, various authors $[7,13,33]$ remind us how CRs vary from one cultural context to another, based on definitions of what $\mathrm{CR}$ is, but also on the licencing frameworks that enable or constrain them. For example, depending on different legislative, ideological and conceptual systems, CR is usually called: popular or educational radio in Latin America; rural or local radio in Africa, free radio in Italy and Germany, associative radio in France, local radio in the Netherlands, neighbourhood radio in Scandinavian countries. Dunbar-Hester [17], writing about the situation in the United States, describes CR stations as legally recognised organisations (in opposition to the pirate radio stations) that usually, but not necessarily, operate with a low power that allows them to transmit within a range of few kilometres.

AMARC, the international organisation of community broadcasters, proposes on its website [2] a description of CR that emphasises the differences within this category: "some are musical, some militant and some mix music and militancy. They are located in isolated rural villages and in the heart of the largest cities in the world. Their signals may reach only a kilometre, cover a whole country or be carried via shortwave to other parts of the world. Some stations are owned by not-for-profit groups or by cooperatives whose members are the listeners themselves. Others 
are owned by students, universities, municipalities, churches or trade unions. There are stations financed by donations from listeners, by international development agencies, by advertising and by governments." [1].

Despite these differences, there is broad agreement about common features. The first is that community media in general, and consequently $\mathrm{CR}$, are organisations that differ from both public service and the commercial organisations $[5,8,13,16,23,25]$. CR stations are usually independent and non-profit; they often use alternative approaches to property and management, based on cooperative models and significant amounts of voluntary work; they propose different types of content and representations, more related to local situations; there is a strong intersection between the social space of the radio and the one of the audience.

The second feature common to many community media lies in the shared objective of supporting citizens, community members, and ordinary people, to have access to the democratic processes. Usually, CR stations offer to non-professionals the possibility to participate in the communication arena through horizontal models of decision making, encouraging processes of empowerment, promoting dialogue, inclusion and the construction of identity $[8,22,23]$. Often CRs are the node, the meeting point, of different organizations and movements, as in the case of Radio Fragola, in Italy, that gives voice to different actors and organisations related mostly to the area of mental health in the city of Trieste, or Radio Corax, a station that gathers actors belonging to the field of social movements in Halle (Germany).

Even if the Internet has given the possibility to CR stations of becoming global, the third common characteristic is their range of transmission - often reduced to a local context: this does not necessarily mean that their audience is composed of few people, as demonstrated by a large number of listeners of CR stations located in urban centres [17,25].

In summary, then, the variety of definitions of CR contributes to the institutioning process, through the policy frame, while the commonalities to the ideal of $\mathrm{CR}$ also plays a role. In the next section, we will see how a specific project, Grassroots Radio ${ }^{1}$ (henceforth GR), provides a technology that allows local communities to develop and manage low-cost CRs.

\section{RootIO, the experience in Uganda and the Grassroots Wavelength project}

The GR Project started in January 2018 and is funded through the European Commission's Horizon 2020 framework, under the forward-looking Collective Awareness Program (CAPS). The consortium is coordinated by the Madeira Interactive Technologies Institute (M-ITI) and includes nine partners from Belgium, Ireland, Portugal, Romania, and the UK, ranging from Universities, civic associations, investigative journalism organisations, AMARC to ICT companies. In order to understand

\footnotetext{
${ }^{1}$ The original name of the project, also present in the legal documentation, is "Grassroot Wavelengths project". For more information, visit the project website at http://grassrootsradio.eu.
}

the main goals of this group of actors, a description of RootIO, the technology at the core of the project, is necessary.

RootIO is a free/open hardware and software stack that allows the creation of a low budget FM radio station based on an inexpensive smartphone, without the need of a studio (Figure 1). As described on the RootIO website: "Using any basic phone, local hosts can run live shows with callers; local business people can record ads or announcements; citizen journalists can cover live meetings or sports events; community members can listen on FM radio, and interact with the station through the Web and their phones" [32]. This technology provides all the connectivity and functions of a larger station for $1 / 100$ th of the cost.

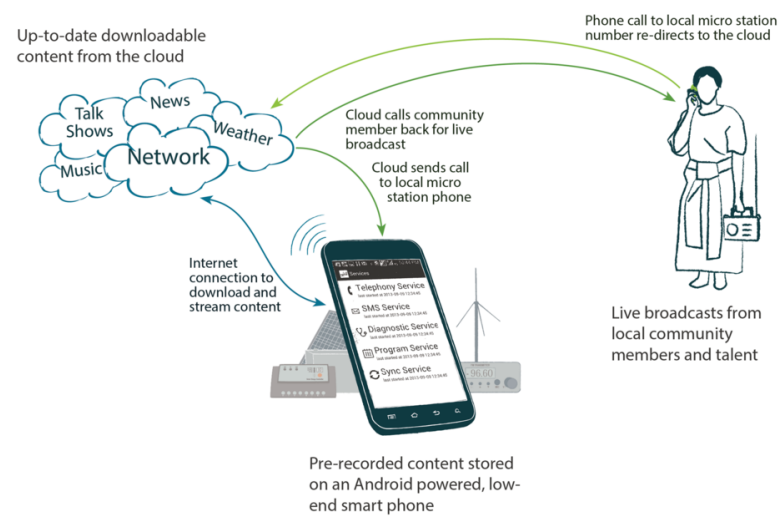

Figure 1 RootIO system for radio and peer to peer information platform (Image credit: Caresse Haaser/RootIO.org)

The design and development of RootIO started in 2013, by a telecommunications engineer and a technologist and professor, both affiliated with M-ITI. Four stations have been running in Northern Uganda for the last year [12].

Through the use and development of the RootIO platform, the GR Project has been working to create a network of low-power CR stations aimed at supporting citizen engagement, community deliberation, media pluralism and the free flow of information within and outside discrete geographic communities. The project approach includes features of participatory design for setting up stations and services and understanding the processes in which they will be used and appropriated, with the involvement of community groups, journalists, and public good experts. Part of the project concerns the implementation of technologies related to synthetic speech in order to transform textual data into audio and, in this way, broadening the possibility of contents that can be broadcasted.

The communities involved since the project proposal are groups of people defined by geographical boundaries: remote and isolated locations across Europe, including Ireland (small islands off the south-western coast of County Cork), Portugal (remote areas in the island of Madeira), and Romania (the area of the south-western province of Oltenia, and the southeastern Danube Delta region). In each of these areas, there is the presence of 
project's community partners, namely GR consortium members working to engage local people with whom to set up the stations.

As defined in the Project Grant Agreement, part of the project focuses on the consideration of the institutional aspects related to the design and the implementation of this technology, with the goal of supporting the communities to "develop, thrive and engage in effective strategies for transforming existing practices and institutions" [37], also through the proposal of policy drafts at national and European level.

As anticipated, we will look at this project asking ourselves the following questions: how does the institutioning process enable and constrain design processes oriented to the making of grassroots communities? What are the practices that designers and communities develop to act in relation to institutions? How can design support grassroots communities' practices considering the different institutional contexts?

\section{Method}

The authors actively take part in the project in different ways. The second author supported the writing of the project proposal; the first and third authors are active consortium members and participate as academics in bi-weekly consortium meetings, and are engaged in fieldwork in two of the three projects sites. The empirical data for this project draws on five in-depth interviews conducted with project partners regarding the process of obtaining a CR license in each of the project countries - Ireland, Romania and Portugal. The process in Uganda is also included, as this experience preceded and influenced the design of the European project. These experiences were triangulated with an interview with the Secretary-General of AMARC to collect information from a wider point of view.

The focus on the licensing process follows the theoretical interest in the relation between institutions and grassroots communities, as licensing turned up to be since the beginning a crucial step in making CRs possible. The additional empirical material analysed is composed of internal documents as project reports, minutes of project meetings, fieldnotes and the consortium mailing list. External documents include the Project Grant Agreement, institutional policy reports, informational materials (press releases, institutional web pages). All data have been analysed through a content analysis [11] framed by our theoretical questions on institutioning.

\section{The Licensing processes}

\subsection{An overview}

The GR project and its consortium are the results of a grant agreement between the project partners and the European Commission, under a particular institutional funding line called CAPS, and this agreement sketches out the boundaries of action for the consortium. Moreover, the project proposal has been built in a way that reflects the requests of the funding agencies, including an interpretation by the GR team of what would look like a good consortium composition, capable of achieving the declared objectives.

That is not the only case in which the institutional framework participated in the definition of the project. For example, several international organisations, for instance, UNESCO [35], CoE [10] and the European Commission [33], have connected the CR sector to the field of human rights and media pluralism, through a range of policies, and that has been reflected in the project proposal and the evaluation.

At the international level, NGOs such as AMARC and the Community Media Forum Europe (CMFE), work on the development of the sector through continuous support, lobbying and advocacy. The Secretary-General of AMARC International stated, during the interview, that "at the international level, CR stations are more recognised than at the national level. The implementation by every country of the international definitions would represent a huge step forward", when referring to facilitating $\mathrm{CR}$ emergence and societal role.

Laws, bylaws and regulations that define the boundaries of CRs are usually established at national level, where the various broadcasting and communication regulatory authorities operate. As we will see, the lack of implementation of international guidelines, the lack of legislation, and of a common standard definition of $\mathrm{CR}$ create ambiguity in the regulation in some countries.

\subsection{The process in Uganda}

Uganda is not part of the GR Project, but it is the country in which RootIO was first introduced, leading to the creation of four local CRs, and offer insight from a socio-cultural and institutional context different than the ones of the GR project. While nearly every station in Uganda describes itself as a community station, they are, in fact, mostly big organisations, funded by multinational advertisers, and with millions of listeners. The adjective "community" is often based just on the fact that these radios are located in rural areas [12]. Despite the linguistic presence of CRs, CRs are largely absent from institutional documents, with the closest mention relating to rural communication development by the Uganda Communications Commission (UCC, the national communications regulator).

Liberalisation of the Ugandan broadcasting space, in the 1990s increased the number of stations from 3 to 200. The dominant business model is to attract the most number of listeners as possible, and to sell expensive advertising spaces, usually to multinational telcos and beverage companies [12]. With this backdrop, RootIO and its concept of low power stations, managed by the community, in order to engage the people in the production of information and public deliberation processes, represent something new.

The RootIO team sent a formal request for licenses to the UCC at the end of 2013, and were granted provisional licenses in December 2014 and launched the four stations in 2015.

Due to the novelty and particularity of the technology and to the absence of rules able to define the features of a CR station, the steps followed to obtain the licenses have been not easily predictable. The RootIO team had to follow a hybrid process, 
producing the documentation that usually is requested to commercial radios, considering also the rural communication development policy, and at the same time providing additional documentation about the innovative features of its technology. As a member of the team says "in our case because we were proposing radio at a scale that was unprecedented and also we were proposing a set up that is unlike many FM radio setups, so we had to provide extra justifications, extra substantiation of what we are trying to do and what we are going towards. So we did provide some extra documents".

During this period, the RootIO team tried to engage some new actors to strengthen their network, for instance, some organisations that source and produce grassroots media. They were also supported by the leader of Prometheus, a very popular CR movement in the US [17].

Probably due to imminent political elections, the request for the licenses has been stuck for several months giving the impression, at some point, that these permissions would never be provided.

An accidental meeting was the turning point: a RootIO staff contacted a person to ask for his contribution, due to his expertise, for the definition of the content of a radio program. Fascinated by the project, this person pushed the RootIO team to participate in a contest about ICT solutions organised by a Ugandan university. The RootIO team participated, won the contest and by this way had the possibility to know a representative of ResilientAfrica Network (RAN), one of the contest's founding organisations.

RAN was the ally that permitted the project to gain credibility in front of the UCC within the institutional action frame: they gave much support to the project writing letter to the Commission, arranging meetings etc. It is a common opinion in the RootIO team that if it were not for them, their licenses would have taken much later or maybe they would not at all have been granted.

Currently, the RootIO team has been reflecting on the possibility to multiply the number of communities that can rely on a single license through a more efficient use of the frequencies: this would sharply increase the possibilities for the community voices in the media field sharing the burden of the bureaucratic procedure.

\subsection{The process in Portugal}

In Portugal, there is no special legal recognition for CRs. Some non-profit organisations run radio stations that in some ways resemble CR stations, but either they operate precisely like regular commercial stations or they make the programs exclusively for the Internet $[19,29]$.

At the beginning of 2018, the community partners belonging to M-ITI began negotiations with the regional representative of the national communication regulator (Autoridade Nacional de Comunicações - ANACOM), in order to obtain CR licences to establish stations in Madeira. From the beginning, ANACOM stated that no long-term licenses for $\mathrm{CR}$ could be provided in Portugal, due to the spectrum regulations and an institutional belief in the lack of possibility for new radios to be economically

\footnotetext{
${ }^{2}$ Partner of the GR Project, the Bere Island Project Group (BIPG) is a community
} group serving Bere Island that aims to sustain the population level by creating sustainable. As described by a member of M-ITI involved in the project: "from what I've been told, so, there has been no new radio station in 20 years because there's been no auction. And there's no legal status of CR in Portugal". Despite this, ANACOM was collaborative and provided temporary experimental licenses specifically designed for researchers, which has enabled the RootIO team to set up stations.

M-ITI was asked to give a presentation of the project in front of a delegation of ANACOM: the focus was not on how these new radios can be a tool to empower isolated communities but to support the management of emergency situations. In the recent past, Madeira has experienced a flood and a big fire that are still in living memory.

ANACOM offered temporary experimental licenses that permitted the setting up of more radio stations for a period of three months. These operating licenses need to be continuously renewed. It appears that ANACOM can grant temporary licences that cannot be longer that 6 months, but it is not yet clear which are the factors that are considered in order to assign different temporal ranges.

It is interesting to underline an episode happened interacting with local institutions: in one of the two potential settings of the CR stations, the antenna was mounted on the roof of the school. In a meeting with the school board, they expressed their concerns about the contents of a radio station that was hosted in a public building.

\subsection{The process in Ireland}

In recent years, several policies have been implemented to support community media development in Ireland [14,19,33]. In fact, Irish CR began through a pilot scheme from the National Broadcasting Authority (BCI/BAI) that established 14 initial CR stations [19]. Since that initial pilot, the sector has further expanded with $17 \mathrm{CR}$ stations and 5 community of interest radio stations currently operating nationwide [4]. The BAI supports radio stations through evaluation, training programs and ensures that $\mathrm{CRs}$ are community managed, run and distinct from the commercial radio sector in Ireland [23].

At the same time, CRs can rely on the help of the CR Forum of Ireland (CRAOL), an umbrella organisation with the functions of representation, lobbying, coordination, training, and support. CRAOL receives funding from the BAI. They publish documentation on their website.

The community partners of $\mathrm{BIPG}^{2}$ describes the process to get a license as potentially time-consuming and technically complicated, as stated by one of its members "what you do need is technical expertise because a lot of the questions relates to how far is the range of the frequency, and you've got a map of the area to make sure that all of the area that you want to cover can be covered". At the same time the transparency of the different steps, the openness of the BAI staff and the support of the CRAOL have made this procedure straightforward.

employment, and to promote community initiatives and support local community projects. 
BIPG applied in September 2018 for a temporary 30-day license, which enables Bere Island to broadcast radio content on FM for 30 days of the calendar year. The application was successful, and the licence was received on 12 December 2018. The entire process was undertaken by email.

The interviewee described BAI representatives as strongly interested in the results of the GR project but also concerned about the consequences of a technology like RootIO. If RootIO enabled a potential increase in the number of $\mathrm{CR}$ stations, control of $\mathrm{CR}$ operations and content could become more difficult. While the application for the licence in Ireland was relatively straight forward, the definition of CR is deeply ingrained in this country and appears to be based on a strong history of commercial pilot radio stations that existed in the past. There is also strong peer support to Bere island from CRAOL, and other CR stations, which may result in the reimagining of radio that RootIO requires (e.g. not having a physical studio) being difficult. While a physical studio space is not required for a 30-day licence, should BIPG consider a 100-day licence, current requirements include a physical radio station. How this can be navigated is yet to emerge.

\subsection{The process in Romania}

CRs are mentioned in Romanian law, but no specific regulations are available to designate their status and standards. As a result, there are no CRs on the FM. In 2007, a European Parliament's [19] report referred to 10 radio stations broadcasting over the internet.

In order to get a license, the RootIO team, with the support of the community partners of ActiveWatch ${ }^{3}$ and MedAlert ${ }^{4}$, had to follow the standard procedure designed for commercial radio stations. This process has been described, by an Active Watch representative, as very long, complicated and difficult, and prohibitively expensive for communities without professional radio skills. As one of the Romanian partners says: "we had to prepare a lot of legal paperwork, and also we had to prepare an editorial strategy, an editorial project, a financial project, describe in detail the scheduling, but I mean like for each minute, really in detail [...] you have to come with a professional application".

The request was submitted to the National Audiovisual Council (Consiliul Naţional al Audiovizualului - CNA), the regulatory authority focusing mainly on the radio contents. A Council of 11 members governs CNA.

The radio frequencies and the licenses are assigned through auctions, organised by CNA, that are infrequent: one auction was held in 2015, none in 2016, two in 2017 and one in 2018. Active Watch knew by chance that one of these auctions was planned at the beginning of 2018. The first step for the RootIO team (guided by Active Watch) was asking CNA to add two frequencies related to the two interested Romanian towns on the list of the frequencies available for the auction.

CNA asked The National Authority for Management and Regulation in Communications (ANCOM) to define these two frequencies that were, finally, added to the list. At this point, the RootIO team was asked to provide much documentation about its

\footnotetext{
${ }^{3}$ Partner of the GR Project, ActiveWatch is a Romanian human rights organization
} that promotes free communication for the public interest. organisation, the editorial project, the technical project, the economic plan, and various background materials. Two competitors applied for the same frequencies.

In June 2018, the team presented the radio projects in front of the CNA members. Both the licenses were assigned to the RootIO team, with just two council members voting against this project: their hostility can probably be explained by the difference of opinion, in particular, about the concept of "public media", between them and Active Watch, and also by previous conflicts. The Romanian CNA is an organisation whose members have a strong political commitment. The councillors' interpretation of the CR stations is influenced by their political view and, for better or worse, by their opinion about Active Watch, a well-known watchdog in the field of media and communication.

For the first time in Romania two CR station licenses have been issued. However, the goals of ActiveWatch are more ambitious: they want to collect evidence about the need to give more voice to the communities and to improve the policy frame and environment. The organisation has already worked with AMARC to design a policy proposal for a new community media regulation in Romania.

Active Watch and MedAlert were forced to apply for a commercial license, starting a journey in a complex and unknown territory. The consequences were continuous requests for information to the public officers not only regarding the process but also about the rules of the game. As the licenses were assigned through an auction, many CNA officers were cautious about giving information about the process in order to not favour any individual competitor. Active Watch suggests that just the more skilled officers were confident to give support about the application process: sometimes it was just a matter of being lucky to find them in the office and not their less cautious colleagues.

\section{DISCUSSION}

At the beginning of the paper, we asked ourselves the following questions: how does the institutioning process enable and constrain design processes oriented to the making of grassroots communities? What are the practices that designers and communities develop to act in relation to institutions? How can design support grassroots communities' practices considering the different institutional contexts?

We showed that answering these questions is important to investigate the relation between design and institutions when technologies for and with communities are at stake. This is necessary since we described two main problems in this area of design: first, the empirical instances of what we can call communities are constantly in the making and the "space vs interest" dichotomy needs to be better discussed; second, institutions as well as communities play a role in shaping - and are potentially shaped by - the design process.

We have underlined how grassroots communities, at the intersection between geographical space and the sharing of the

\footnotetext{
${ }^{4}$ Partner of the GR Project, MedAlert is a Romanian nonprofit organisation specialized in health care journalism and patient advocacy.
} 
practices/interests, are a good starting point to investigate the relation between design and institutions in the design of technologies for and with communities.

For this reason, we have then introduced the GR project focusing on its objective to define solutions for participatory innovation in the domain of media pluralism supporting the creation of a network of $\mathrm{CR}$ stations based on grassroots communities, and in particular we focused on the process of obtaining a licence to operate radio stations.

Following the academic debate about design as institutioning $[24,28,34]$ we have structured the research within the space of interaction between the institutional frames described by Huybrechts and colleagues [24] and the institutional constraints described by Lodato and DiSalvo [28], never forgetting the influence of the different geographical contexts. The next sections will illustrate the role of these institutional frames and constraints.

\subsection{Sharing institutional constraints and good practices between communities}

8.1.1 The Sandbox. With the help of Table 1, we can see (first column) that most of the countries observed do not have a specific policy frame about CR station, with the exception of Ireland. This situation forces the community partners involved to move to different frames to enable their CR stations. These are the rural communication development in Uganda, the experimental licenses in Portugal, the commercial license in Romania, different sets of rules that create the conditions for the presence of a sandbox that potentially limits the possibility for innovation. Ireland proved to be the only country where the CRs' policy frame is well defined, easily understandable and accessible. However, as mentioned earlier, in Ireland, the policy environment potentially acts as a sandbox, through its definition of what community radio is, and definitions of what a radio station is, different from the model that GR promotes, one that does not rely on a physical station. While it is too early to understand the relation between these two opposite forms of sandbox on the development of $\mathrm{CR}$ in these communities, it will be interesting to explore this in the future.

\begin{tabular}{|l|l|l|l|}
\hline \multicolumn{1}{|c|}{ Frames } & Policy & Instit. Action & Metacultural \\
\hline International & $\begin{array}{l}\text { Grant } \\
\text { agreement }\end{array}$ & $\begin{array}{l}\text { Project } \\
\text { proposal } \\
\text { evaluation }\end{array}$ & $\begin{array}{l}\text { Public vs } \\
\text { private }\end{array}$ \\
\hline Uganda & $\begin{array}{l}\text { Rural comm. } \\
\text { dev. }\end{array}$ & & $\begin{array}{l}\text { CRs are } \\
\text { commercial }\end{array}$ \\
\hline Portugal & Exper. licenses & & Tackle emerg. \\
\hline Ireland & CR Licences & & \\
\hline Romania & CR rules & & \\
\hline
\end{tabular}

Table 1: Potential frames of sandbox in the different countries and at the international level

At the international level, it is important to underline how the Grant Agreement can be considered a sandbox for the design process at the policy frames: it sets several boundaries that can afford and limit the possibilities of innovation. As described by Teli et al. [34] the success or the failure of the project will be judged within the framework defined by this agreement, where also the modalities for the management of the partner interactions are set. At the same level but in the Institutional action frame, the project evaluation process had a strong influence on the definition of the communities involved. At the metacultural frame (third column), instead, we observe a representation of the radio that is still strongly influenced by the dichotomy public vs private.

Regarding the analysis of the metacultural frame in the single countries (third column), the design process in Uganda is influenced by the liberalisation that happened in the 1990s and its commercial business model. In Portugal the presence of isolated communities and the memory of recent situations of emergency represent a narrative that strongly influences the process: this frame has been very useful to show the potential of the project, but at the same time can reinforce the sandbox created by the use of experimental licenses. The identity of the radio can be confined to a simple tool that must be used only in emergency cases.

8.1.2 The Administrative Gap. (Table 2). In the three countries where the policy frame is less clear (first column), the community partners have to deal with the increasing of the institutions' discretionary power, with the risk of administrative gaps: this means that the institutions are less engaged in activities of long term planning. This is evident in Romania, where the process is unpredictable, but also in Uganda and Portugal (second column).

In Portugal, the regulator claims there is no possibility to issue new long-term licenses, as the radio limit has been reached. In Ireland, the risk of an administrative gap is based on the BAI's concern of losing control of the numerous CR stations that RootIO could allow, through reducing the costs and barriers for communities that wish to set up a radio station.

In general, the fact that Uganda, Portugal and Romania do not adopt the international definitions of $\mathrm{CR}$ relates to administrative gaps.

\begin{tabular}{|l|l|l|l|}
\hline \multicolumn{1}{|c|}{ Frames } & Policy & Instit. Action & Metacultural \\
\hline International & & $\begin{array}{l}\text { No adopt. of } \\
\text { internat. defin. }\end{array}$ & \\
\hline Uganda & $\begin{array}{l}\text { No rules about } \\
\text { CRs }\end{array}$ & $\begin{array}{l}\text { Process not } \\
\text { predictable }\end{array}$ & \\
\hline Portugal & $\begin{array}{l}\text { No rules about } \\
\text { CRs }\end{array}$ & Full spectrum & \\
\hline Ireland & & $\begin{array}{l}\text { Concern about } \\
\text { losing control } \\
\text { of the CRs }\end{array}$ & \\
\hline & $\begin{array}{l}\text { No law } \\
\text { implement on }\end{array}$ & $\begin{array}{l}\text { Process not } \\
\text { predictable }\end{array}$ & \\
Romania & CRs & \\
\hline
\end{tabular}

Table 2: Elements influencing the presence of Administrative Gaps in the different countries and at the supranational level

8.1.3 The Ideological mismatch. Observing Table 3, it is evident (third column) how the practices of all the community partners and the actors considered are immersed in an international 
context where the metacultural frame of neoliberalism and the rule of free markets are predominant and are an obstacle to solutions that can go beyond the contraposition public vs private. Also in this case, Ireland demonstrated to be an exception with the BAI showing a strong interest in public engagement and civic participation.

In Uganda the reluctance of UCC to give the licenses during the electoral period together with the RootIO team's necessity of continuous modelling of its project network, in order to find new allies that could be considered as "trusted" by the regulator, is also a clear example of the presence of an ideological mismatch (second column). The same institutional constraint is nourished in Romania by the divergence of opinions and the contrasts between Active Watch and a strongly politicised regulator.

At the local level, the case of the Portuguese school shows how the design process needs to deal with an ideological mismatch when negotiating with local institutions concerned with reputation.

In the next section, we will see the practices that designers and grassroots communities in the making develop to act in relation to the institutional frameworks and their constraints.

\begin{tabular}{|l|l|l|l|}
\hline \multicolumn{1}{|c|}{ Frames } & Povel & Instit. Action & Metacultural \\
\hline International & & & $\begin{array}{l}\text { Neoliberalism; } \\
\text { free-market }\end{array}$ \\
\hline Uganda & & politicisation & $\begin{array}{l}\text { Neoliberalism; } \\
\text { politicisation }\end{array}$ \\
\hline Portugal & & reputation (local level) & Neoliberalism \\
\hline Ireland & & & Neoliberalism \\
\hline Romania & & $\begin{array}{l}\text { politicisation; "media" } \\
\text { representation }\end{array}$ & $\begin{array}{l}\text { Neoliberalism; } \\
\text { politicisation. }\end{array}$ \\
\hline
\end{tabular}

Table 3: Elements influencing the presence of Ideological

Mismatch in the different countries and at the international level

\subsection{Practices to face the institutional frameworks}

8.2.1 Setting the grassroots radio station within the sandbox. The first columns of Table 1 and Table 2 show that in most of the countries that we observed, there are no specific rules related to the creation of CRs. The path that the community partners have been trying to follow is to adapt the project to the most similar policy frame available. This is what happened in Romania, with the commercial license, in Uganda, with the commercial license and the rural communication development frame and in Portugal with the experimental research licenses.

Table 1 shows us that the main consequence of the lack of a specific policy frame is the creation of a sandbox that limits the potential innovative features of the technology that has to be designed. In order to proceed with the design process, the community partners adapt their goals to the new policy. What is interesting, is that at the same time there are some plans of institutional change that are activated, as we can see, in Romania with the design of a new policy proposal.

The situation in Ireland is different. In this country the documentation, the agenda, the rules are transparent, and the information easily accessible. As a result, the community partners and the local people involved can count on tools, techniques and approaches already present and tested. These conditions can improve the possibility of the participation of lay people, which can easily find support from institutions such as CRAOL and the Broadcasting Authority, as well as other CRs. At the same time, we noticed, together with some previous literature, how the Irish policy frame through its narrow definition of what $\mathrm{CR}$ is, misses the potential for some of the transformative social and political changes evident in other contexts and supported by the AMARC charter. We saw, then, that this particular policy frame, in Ireland, acting as a sandbox, has the potential to impact also in the civic engagement itself as discussed more widely by Gaynor and O'Brien [23], while also having the potential to reignite civil society through a policy environment [21], which supports community ownership, management of stations and through regulation retains the distinctiveness of the $\mathrm{CR}$ sector, from its commercial sector [22].

8.2.2 Navigating the uncertainty through legitimising social relations. The lack of a specific definition regarding CR stations in Portugal, Romania and Uganda has the effect of creating ambiguous institutional action frames (Table 2 - second column): the interaction between the project and the regulatory authorities are not easily predictable with the consequence of making the planning process very complex, resulting in the adaptation of $\mathrm{CR}$ to rules not designed to support it. Access to information is based on the construction of trusted relations with public officers, willing to support community partners to navigate the institutional framework to get the information they need.

In order to get the licenses, the various partners interacted with the regulator and various other supporting organisations, in a variety of ways. In contexts of high uncertainty then, they are forced to find alternative ways, outside the policy frame, to understand what is expected of them. They must establish relationships with trusted others, who can support their application process, which in turn, extends the boundaries of the community, through allies that support their process, and by proxy extend their legitimacy to the communities seeking licences, in an act of recognition. At the same time, the project's narrative needs to be modified in order to find a compromise between the initial goals and the institutional requests. It is evident that the challenges are high for each community partner, without the support of allies, and the sourcing of information outside existing frameworks. A not very predictable situation can be the trigger for potential administrative gaps that the GR project tries to avoid through supporting the communication of the grassroots community with the institutions and the sharing of relevant information.

8.2.3 Overcoming ideological mismatch through critical mass and media allies. The metacultural frames are the area where the technology design process and the communities involved have to deal with institutional constraints related to political and ideological issues and with the interpretation of broad narratives (Table 1 and 3 - third columns). 
In general, there is a potential ideological mismatch between the goal of the project to support citizen engagement, community deliberation, media pluralism, the free flow of information and the neoliberal metacultural frame based on the rules of the market and a strong individualism and sometimes the politicians' electoral interests. For small communities, the challenge to compete with huge organisations under their rules is most of the time unfair. We saw there is a robust institutional consensus about citizen engagement and media pluralism, but at the same time, there are still many obstacles to reach these goals. The solution proposed by the project is to provide the grassroots communities, through the community partners, with the support of trusted guarantors and the creation of a critical mass.

Now we can move to see how design can support these grassroots communities' practices considering the different institutional contexts.

\subsection{Fostering a network of grassroots communities of practice in the making}

The GR project is trying to design and implement a technology that is very controversial from two points of view.

First of all, the project introduces an innovative technology as detailed in Figure 1, to replace some features of well traditional media used for CR, which is defined by institutional frameworks and strongly regulated. The result of this interaction is that taken for granted situations become evident, underlying dynamics of discrimination and disparity in access to the information. This is evident, for instance, in countries where regulators have never implemented rules for CRs: here, to have a license, the community partners have to compete with big media corporations. We saw that the strategy they used to face these situations is to adapt their goals to the existing rules. We saw that this creates the basis for a change, like in Romania where there is the attempt to design new policies with the help of AMARC. It is interesting that this new technology also questions the grassroots community emerging from an institutional best practice like Ireland: as its institutional framework potentially limits the reimagining of CR. In this case, we can say that the design process allows the communities to call into question the contents of the institutional frameworks through discussion with similar communities in other places.

On the other side, the GR project has questioned the dualism between space and practice in the definition of the communities engaged. RootIO is a technology with a strong geographical connotation: it makes limited transmission range one of its main features. The GR project itself promotes the goal of addressing local communities to allow them to reclaim communication, discussion and deliberation tools that are now mostly, managed nationally or globally. Also, this particular local identity showed various frictions in the interaction with the institutional frameworks: the radio laws are mostly national, local cooperativism is often in contrast with neoliberalism, etc. In these cases, the strategies adopted by the community partners are related to the inclusion of new actors with the role of trusted guarantors and to the association with other community partners in order to create a critical mass.
In this case, through the design process, the community partners and the local people that start to be involved can rely on the recognition and help of legitimising others, in order to establish a dialogue with the institutional authorities.

As we saw, the procedures to obtain CR licenses can lead to the enrichment of the local communities with different assemblages of lay people, technicians, NGOs, laws, by-laws, politicians' expert knowledge, standards, etc. These were necessary to face the main constraints observed in the project interaction with institutions: the lack of information regarding the procedure, the lack of regulations that discipline the particular case, the uncertainty connected with a strong bureaucratization, the subjectivity of some decisions, the complexity of the technical issues, the political influence, the unfair competition between small local communities and big commercial organizations sometimes led by politicians. In the different areas were the design activities have been set, we observe the need of attracting these actors and their competence from the outside maintaining at the same the focus to the local challenges.

This process can help community members willing to set up a radio station better deal with institutional frames and, when it is necessary, to try to modify them. Such a change is possible through the design of a common infrastructure where the different community partners and the local people involved can co-create solutions to deal with the respective local institutional frames and form a critical mass, to advocate for change at the national or international level. While in Ireland some resources were already institutionally stable through the support of BAI and CRAOL, in the other countries the process has been more challenging and based on trials and errors: sometimes serendipity played a role, for instance when the RootIO team, participated in an ICT challenge that enabled a collaboration with the ResilientAfrica Network (RAN). The making of a grassroots community is also based on contingencies: the role of the design is also to facilitate these processes.

\section{Conclusion}

Based on the recent debate regarding the Institutioning processes within design, in this paper we have highlighted the transformations undertaken by a group of geographic communities involved in a European project of technology design. In particular, we have underlined how, in pursuing the goals of the design process, the project's community partners and the local people involved need to deal with specific institutional constraints related to different institutional frames. The empirical case of the GR project has served to evidence, from a comparative perspective, the main elements that contribute to the emergence of these constraints. We described the practices used by the actors involved to deal with the institutional frames and their constraints: adapting the project's goals to the policy frames in use and at the same time working to modify the institutional frame; extending the boundaries of the community partners and of the grassroots community in the making outside the local space to involve new legitimising social relations; overcoming ideological mismatches through critical mass and the sharing of 
information with similar community partners and grassroots community involved in the same project. The design process has the possibility to boost these dynamics underlying situations of discrimination and disparity in access to the information and working as a platform where actors' knowledge and good practices can be shared between the different grassroots community in the making crossing the local boundaries.

Finally, future research is needed to investigate the transformation concerning the grassroots community, the institutional frames and the design goals, taking place during the design project in the different contexts.

\section{ACKNOWLEDGMENTS}

The Grassroot Wavelengths Project has received funding from the European Union's Horizon 2020 Research and Innovation Program under Grant Agreement No 780890. 


\section{REFERENCES}

1. AMARC. 1995. Report on the Sixth World Conference of Community Radio Broadcasters.

2. AMARC. AMARC website. Retrieved February 2, 2019 from http://www.amarc.org/?q=node/47

3. Benedict Richard O'Gorman Anderson. 1991. Imagined Communities: Reflections on the Origin and Spread of Nationalism. Verso, New York.

4. BAI. 2019. List of TV and Radio Stations. Broadcast Authority of Ireland. Retrieved February 21, 2019 from https://www.bai.ie/en/broadcasters/

5. Donald Browne. 2012. What is "Community" in community radio? A consideration of the meaning, nature and importance of a concept'. In f. Gordon (ed.) Community Radio in the Twenty First Century. Peter Lang, London and New York, 153-74.

6. Federico Cabitza, Carla Simone, and Denise Cornetta. 2015. Sensitizing concepts for the next community-oriented technologies: shifting focus from social networking to convivial artifacts. The fournal of Community Informatics 11. Retrieved February 18, 2019 from http://cijournal.net/index.php/ciej/article/view/1155

7. Nico Carpentier. 2017. The Discursive-Material Knot. Retrieved February 18, 2019 from https://www.peterlang.com/view/title/22797

8. Nico Carpentier, Vaia Doudaki, and Yiannis Christidis. 2015. Technological Struggles in Community Media. In The Routledge Companion to Alternative and Community Media (Chris Atton). Routledge, 483-493.

9. Pål Castell. 2016. Institutional framing of citizen initiatives: a challenge for advancing public participation in Sweden. International Planning Studies 21, 4 305-316. https://doi.org/10.1080/13563475.2015.1124756

10. CoE. 2018. Recommendation $\mathrm{CM} / \operatorname{Rec}(2018) 1$ of the Committee of Ministers to member States on media pluralism and transparency of media ownership. Retrieved February $\quad 18, \quad 2019$ from https://search.coe.int/cm/Pages/result_details.aspx?ObjectId=0900001680790e1 3

11. Amanda Coffey and Paul Atkinson. 1996. Making sense of qualitative data: complementary research strategies. Sage Publications, Inc.

12. Christopher Csíkszentmíhalyi and Jude Mukundane. 2016. RootIO: ICT + telephony for grassroots radio. In IST-Africa 2016 Conference Proceedings. http://dx.doi.org/10.1109/ISTAFRICA.2016.7530700

13. Rosemary Day. 2003. Community radio in Ireland: building community, participation and multi-flow communication. Dublin City University, Dublin.

14. Rosemary Day. 2008. Community Radio in Ireland. Participation and Multiflows of Communication. Hampon Press, Creskill, NJ.

15. Carl DiSalvo and Andrew Clement Volkmar Pipek. 2012. Participatory Design for, with and by communities. In Routledge International Handbook of Participatory Design. Routledge. https://doi.org/10.4324/9780203108543-15

16. Urszula Doliwa and Larisa Rankovic. 2014. Time for community media in Central and Eastern Europe. Central European fournal of Communication 7, 1(12): 18-33.

17. Christina Dunbar-Hester. 2014. Low Power to the People: pirates, protest, and politics in FM radio activism. Retrieved February 18, 2019 from https://mitpress.mit.edu/books/low-power-people

18. Pelle Ehn. 2008. Participation in Design Things. In Proceedings of the Tenth Anniversary Conference on Participatory Design 2008 (PDC '08), 92-101. $\begin{array}{llll}\text { Retrieved } & \text { February } & 18, & 2019\end{array}$ http://dl.acm.org/citation.cfm?id=1795234.1795248

19. European Parliament. 2007. The State of Community Media in the European Union. Brussels.

20. Jan Fernback. 2007. Beyond the diluted community concept: a symbolic interactionist perspective on online social relations. New Media \& Society 9, 1: 49-69. https://doi.org/10.1177/1461444807072417

21. Niamh Gaynor and Anne O'Brien. 2011. Community radio in Ireland:"defeudalising" the public sphere? favnost-The Public 18, 3: 23-28.

22. Niamh Gaynor and Anne O'Brien. 2012. Because it all begins with talk: community radio as a vital element in community development. Community Development fournal 47, 3: 436-447.

23. Niamh Gaynor and Anne O'Brien. 2017. Community radio, democratic participation and the public sphere. Irish fournal of Sociology 25, 1: 29-47. https://doi.org/10.7227/IJS.0002

24. Liesbeth Huybrechts, Henric Benesch, and Jon Geib. 2017. Institutioning Participatory Design, Co-Design and the public realm. CoDesign 13, 3: 148-159. https://doi.org/10.1080/15710882.2017.1355006

25. Nick Jankowski and Ole Prehn (eds.). 2002. Community media in the information age: perspectives and prospects. Hampton Press, Cresskill, N.J.

26. Stacey Kuznetsov, William Odom, Vicki Moulder, Carl DiSalvo, Tad Hirsch, Ron Wakkary, and Eric Paulos. 2011. HCI, politics and the city: engaging with urban grassroots movements for reflection and action. In CHI'11 Extended Abstracts on Human Factors in Computing Systems, 2409-2412.

27. Jean Lave and Etienne Wenger. 1991. Situated learning: Legitimate peripheral participation. Cambridge university press.
28. Thomas Lodato and Carl DiSalvo. 2018. Institutional Constraints: The Forms and Limits of Participatory Design in the Public Realm. In Proceedings of the 15th Participatory Design Conference: Full Papers - Volume 1 (PDC '18), 5:1-5:12. https://doi.org/10.1145/3210586.3210595

29. Miguel Midões. 2016. Community radios in the Portuguese-speaking space: mapping the differences of a community empowerment. Radio, Sound \& Society Journal 1, 1: 13-25.

30. Cristhian Parra, David Nemer, David Hakken, and Vincenzo D'Andrea. 2015 Deep Trust in the future of Community Informatics. The fournal of Community Informatics 11. Retrieved February 18, 2019 from http://cijournal.net/index.php/ciej/article/view/1203

31. Marc Pilisuk, JoAnn McAllister, and Jack Rothman. 1996. Coming together for action: The challenge of contemporary grassroots community organizing. fournal of Social Issues 52, 1: 15-37.

32. RootIO. RootIO website. RootIO Radio -- a technology platform for low cost, hyperlocal community radio stations. Retrieved May 2, 2019 from http://rootio.org/tech

33. Salvatore Scifo. 2014. Communication Rights as a Networking Reality: Community Radio in Europe. In Communication Rights and Social fustice: Historical Accounts of Transnational Mobilizations, Claudia Padovani and Andrew Calabrese (eds.). Palgrave Macmillan UK, London, 164-179. https://doi.org/10.1057/9781137378309_10

34. Maurizio Teli, Peter Lyle, and Mariacristina Sciannamblo. 2018. Institutioning the Common: The Case of Commonfare. In Proceedings of the 15th Participatory Design Conference: Full Papers - Volume 1 (PDC '18), 6:1-6:11. https://doi.org/10.1145/3210586.3210590

35. UNESCO. 2011. Community media: a good practice handbook. United Nations Educational, Scientific and Cultural Organization, 7, place de Fontenoy, 75352 Paris 07 SP, France.

36. UTOPIA Project Group. 1981. The UTOPIA Project. On Training, Technology and Products Viewed from the Quality of Work Perspective.

37. Project Grassroot Wavelengths - GRANT AGREEMENT 